\title{
Erythema Multiforme-Like Skin Reaction Induced by Lenalidomide
}

\section{Christin Kronschläger ${ }^{1 *}$, Michael Erdmann', Annina Wolf', Carla Kellermann² and Lucie M Heinzerling}

${ }^{1}$ Department of Dermatology, University hospital Erlangen, Erlangen, Germany

${ }^{2}$ Department of Medicine, University hospital Erlangen, Erlangen, Germany

\begin{abstract}
The thalidomide analogues, with lenalidomide as the leading compound, have effectivity in the treatment of multiple myeloma and myelodysplastic syndromes. With this class of immunomodulatory drugs immune mediated adverse events are common. Skin eruptions are frequent side effects, ranging from mild exanthemas to the rare but severe Stevens-Johnson syndrome. We report herein a case of an erythema multiforme-like skin eruption in a female patient with multiple myeloma. The reaction occurred during the second cycle of the treatment with lenalidomide and dexamethasone, required cessation of therapy and the application of systemic and topical corticosteroids.
\end{abstract}

Keywords: Lenalidomide; Erythema multiforme; Drug eruption

Abbreviations: EM: Erythema Multiforme; MM: Multiple Myeloma; SJS: Stevens-Johnson syndrome; TEN: Toxic Epidermal Necrolysis; NSAR: Non-Steroidal Antirheumatics; Rd: Revlimid; VMP Regimen: Treatment Regimen including Bortezomib, Melphalan and Prednisone

\section{Introduction}

Lenalidomide (Revlimid ${ }^{\circledR}$; Celgene Corporation, Summit, NJ, USA) in combination with dexamethasone is used for second line treatment of patients with multiple myeloma [1]. In some countries (Argentinia, Canada, USA) lenalidomide is also approved for the treatment of myelodysplastic syndrome and it is actively evaluated for the use in other hematologic tumor entities as well as in solid tumors [2-6]. Lenalidomide is a 4-amino-glutamyl analogue of thalidomide and belongs to a class of novel immunomodulatory drugs. Compared to thalidomide it is reported to have more potent anti-inflammatory and anticancer activities, as well as a better safety profile with a decreased incidence of somnolence, constipation, neuropathy and adverse skin reactions [7].

Dermatological side effects are a known and frequent complication of lenalidomide use [8]. Most eruptions occur in the first month of therapy and have been described as morbilliform, urticarial, eczematous or acneiform [9]. Here we report on a very rare skin reaction.

\section{Case Report}

A 76-year-old female presented to our clinic with a progressive generalized pruritic skin eruption. Ten months before multiple myeloma was diagnosed with diffuse affection of the vertebrae. After surgical stabilization of the spine and postsurgical irradiation of the affected vertebral bodies therapy with bortezomib, melphalan and prednisone (VMP regimen) was initiated. Because of persisting myeloma $\mathrm{M}$ protein VMP regimen was stopped after the $5^{\text {th }}$ treatment cycle and oral therapy with lenalidomide $25 \mathrm{mg}$ for 21 days and dexamethasone $20 \mathrm{mg}$ on days 1,8 and 15 was initiated (Rd regimen with low dose dexamethasone). Temporarily this treatment had to be paused for three days due to impaired general condition, sweating and dizziness. The $2^{\text {nd }}$ treatment cycle began on day 32 with a reduced dosage of $15 \mathrm{mg}$ lenalidomide (dexamethasone $20 \mathrm{mg}$ ). On day 14 of the $2^{\text {nd }}$ cycle (day 45 from treatment initiation) the patient developed erythematous maculae affecting the arms and legs. In the following days these changes spread, subsequently became generalized and were accompanied by itching and fatigue. There was no history of herpes infection in the last weeks, no other infections, NSAR or other drug intake or uncommon food intake. Concomitant long term medication included pregabalin, temazepam, ibandronate every 4 weeks and trimethoprim/sulfamethoxazole three times a week for more than 6 months. The medical history was positive for hypertension, hiatus hernia, osteoporosis and depression.

The clinical picture presented with a generalized maculopapular exanthema, partially confluent to erythematous plaques (Figure 1) with livid plaques on the legs and forearms, and target lesions on the thighs (Figure 2). There was no mucosal involvement. The patient was in good general condition with no signs of infection. The histological analysis revealed focal vesiculation with lymphocytes, and some neutrophils in the epidermis consistant with a drug eruption. In the upper dermis an infiltrate consisting of lymphocytes and eosinophils, accentuated around the postcapillary venules, and scattered in the interstitium is observed. Extravasated erythrocytes and discrete endothelial swelling could be seen without fibrin thrombi or involvement of the deep cutaneous plexus (Figure 3). Lenalidomide, as well as trimethoprim/ sulfamethoxazole were stopped. Methylprednisone $60 \mathrm{mg}(0.85 \mathrm{mg} /$

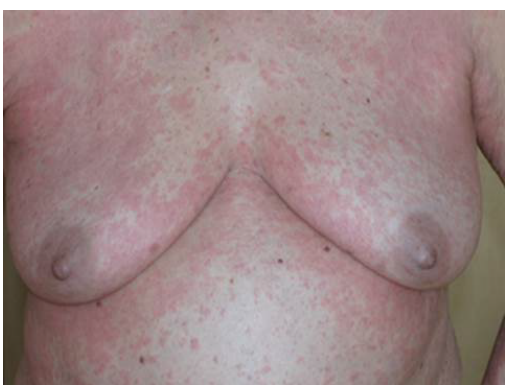

Figure 1: Generalizedmaculopapular skin eruptions on breast and chest.

*Corresponding author: Christin Kronschläger, Department of Dermatology, University of Erlangen, Ulmenweg 18, 91054 Erlangen, Germany, Tel: +49-9131 85 45852; Fax: +49-9131-85 33096; E-mail: christin.kronschlaeger@uk-erlangen.de

Received June 03, 2013; Accepted July 24, 2013; Published July 29, 2013

Citation: Kronschläger C, Erdmann M, Wolf A, Kellermann C, Heinzerling LM (2013) Erythema Multiforme-Like Skin Reaction Induced by Lenalidomide. J Allergy Ther 4: 145. doi:10.4172/2155-6121.1000145

Copyright: (c) 2013 Kronschläger C, et al. This is an open-access article distributed under the terms of the Creative Commons Attribution License, which permits unrestricted use, distribution, and reproduction in any medium, provided the original author and source are credited. 
Citation: Kronschläger C, Erdmann M, Wolf A, Kellermann C, Heinzerling LM (2013) Erythema Multiforme-Like Skin Reaction Induced by Lenalidomide. J Allergy Ther 4: 145. doi:10.4172/2155-6121.1000145

Page 2 of 3

\begin{tabular}{|c|c|c|c|c|c|}
\hline Description of Skin Lesion/ Outcome & $\begin{array}{l}\text { Lenalidomide } \\
\text { stopped } \\
\text { permanently }\end{array}$ & N/Sex/Age, y & Disease & Study Design & Reference \\
\hline $\begin{array}{l}\text { Sweet Syndrome of the hands on day } 6 \text { after initiation of treatment with } \\
\text { lenalidomide. Oral prednisolone } 40 \mathrm{mg} \text { was given and tapered over several weeks. }\end{array}$ & yes & $1 / \mathrm{M} / 57$ & MM & Case Report & $\begin{array}{l}\text { Hoverson AR } \\
\text { et al. [16] }\end{array}$ \\
\hline $\begin{array}{l}\text { Granulomatous dermatitis on the trunk and extremities. The skin eruptions } \\
\text { resolved. }\end{array}$ & yes & $1 / F / 55$ & MM & Case Report & Deng A et al. [19] \\
\hline $\begin{array}{l}\text { Neutrophilic dermatosis on day } 14 \text { after treatment initiation. Clinical improvement } \\
\text { after discontinuation of lenalidomide and initiation of oral prednisolone. }\end{array}$ & yes & $1 / F / 57$ & MM & Case Report & Thieu KP et al. [20] \\
\hline $\begin{array}{l}\text { Acneiform lesions of the head and neck with the finding of Candida albicans at } \\
\text { the end of the 3rd treatment cycle. Lesions resolved } 3 \text { months after lenalidomide } \\
\text { cessation and treatment with topical desonide and oral doxycycline. }\end{array}$ & yes & $1 / \mathrm{M} / 75$ & MM & Case Report & Michot $\mathrm{C}$ et al. [21] \\
\hline $\begin{array}{l}\text { Mildly pruritic truncal eruption within the } 1 \text { st week after treatment initiation with } \\
\text { lenalidomide for MM. Treatment was discontinued because of edema, fatigue, } \\
\text { dizziness, gastritis and this skin eruption. } 2 \text { months later AM was diagnosed and a } \\
\text { combination treatment with lenalidomide, dexamethasone, and melphalan begun. } \\
\text { Purpuric skin eruptions appeared within } 1 \text { week of combination treatment. }\end{array}$ & yes & $1 / \mathrm{M} / 74$ & $\mathrm{AM}$ and $\mathrm{MM}$ & Case Report & Kuohung et al. [22] \\
\hline $\begin{array}{l}\text { Blaschkitis along the left leg, the trunk and the left arm in the } 4 \text { th month after } \\
\text { treatment initiation. Disappearance of eruptions during drug-free intervals and } \\
\text { reappearance after restart of treatment. }\end{array}$ & no & $1 / \mathrm{M} / 60$ & MM & Case Report & Grape J et al. [23] \\
\hline $\begin{array}{l}\text { Macular skin eruptions evolving to SJS after the end of the } 1 \text { st treatment cycle. A } \\
\text { symptomatic treatment with methylprednisolone, itraconazole, antihistamines and } \\
\text { antiseptics was initiated. Skin lesions resolved after } 30 \text { days. }\end{array}$ & yes & $1 / F / 69$ & MM & Case Report & Allegra A et al. [13] \\
\hline 3 patients developed skin reactions, 1 urticaria, 1 EM, 1 SJS. & $x$ & $\begin{array}{l}2 / \mathrm{F} / 70,81 \\
1 / \mathrm{M} / 62\end{array}$ & MM & Case Reports & Penna G et al. [14] \\
\hline $\begin{array}{l}\text { SJS/TEN overlap appearing during the } 2 \text { nd treatment cycle. Discontinuation of } \\
\text { lenalidomide, systemic corticosteroids and intensive supportive care led to clinical } \\
\text { recovery. }\end{array}$ & yes & $1 / \mathrm{M} / 61$ & MM & Case Report & Wäsch R et al. [15] \\
\hline $\begin{array}{l}\text { Skin eruptions progressing to SJS beginning on day } 24 \text { of the } 11^{\text {st }} \text { treatment cycle. } \\
\text { Progress of symptoms after initiation of prednisolone and antihistamines. Recovery } \\
\text { under corticosteroids, high dose IVIG, prophylactic antibiotics and fluid input. }\end{array}$ & yes & $1 / \mathrm{M} / 51$ & PCL & Case Report & $\begin{array}{l}\text { Siniscalchi A } \\
\text { et al. [16] }\end{array}$ \\
\hline $\begin{array}{l}12 \text { reports of SJS, } 3 \text { reports of EM, } 1 \text { report of TEN. The median time of onset of } \\
\text { event was } 24 \text { days (3-45) from start of lenalidomide. }\end{array}$ & $x$ & $\begin{array}{l}7 / \mathrm{F}, 5 / \mathrm{M} \\
(\text { median } 63,5 \\
50-83)\end{array}$ & $\begin{array}{l}\text { MM } \\
\text { MF } \\
\text { AM }\end{array}$ & $\begin{array}{l}\text { Case Reports } \\
\text { from market } \\
\text { launch } \\
12 / 2005- \\
06 / 2008)\end{array}$ & $\begin{array}{l}\text { Castaneda CP } \\
\text { et al. [12] }\end{array}$ \\
\hline $\begin{array}{l}\text { Skin eruption were described as morbilliform }(\mathrm{N}=22) \text {, urticarial }(\mathrm{N}=6) \text {, dermatitic } \\
(\mathrm{N}=2) \text {, acneiform }(\mathrm{N}=1) \text { and undefined }(\mathrm{N}=1) \text {. }\end{array}$ & $x$ & $\begin{array}{l}22 / x / x \\
10 / x / x\end{array}$ & MM & $\begin{array}{l}\text { Retrospective } \\
\text { review of } \\
\text { medical } \\
\text { records }\end{array}$ & Sviggum HP et al. [9] \\
\hline
\end{tabular}

Abbreviations: AM: Amyloidosis; EM: Erythema Multiforme; F: Female; IVIG: Intravenous Immunoglobulins; M: Male; MF: Myelofibrosis; MM: Multiple Myeloma; N: Number of Patients; PCL: Primary Plasma Cell Leukemia; SJS: Stevens-Johnson Syndrome; TEN: Toxic Epidermal Necrolysis; x: Not Listed; y: Years

Table 1: Reported adverse skin events in patients treated with lenalidomide.

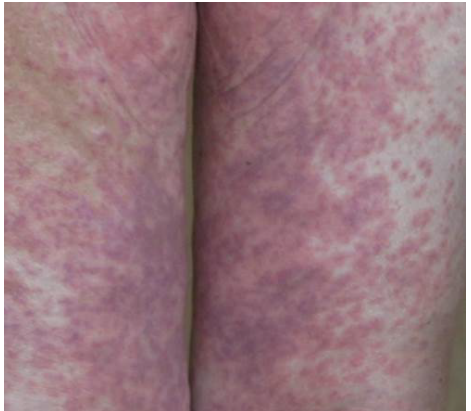

Figure 2: Clinical presentation of EM-like skin eruptionson the thighs.

$\mathrm{kg}$ body weight) orally, topical corticosteroids (Class III) as well as antipruritic treatment with topical polidocanol $5 \%$ in unguentum leniens and systemic $\mathrm{H} 1$ blockers were given. This treatment resulted in a fast improvement of the skin manifestations. After 3 days the systemic medication with methylprednisolone could be reduced and after 5 days it was stopped. Furthermore, tapered use of local class III corticosteroids until complete remission of the skin eruption was recommended. When skin changes had stopped lenalidomide was reinitiated. Since trimethoprim/sulfamethoxazole, was planned to be stopped 3 months after cessation of VMP treatment, it was not restarted. Interestingly, despite the severe skin reaction the $3^{\text {rd }}$ treatment cycle with lenalidomide and dexamethasone (15 $\mathrm{mg}$ and $20 \mathrm{mg}$, respectively) was conducted for the planned 21 days without any adverse events.

\section{Discussion}

This article reports on a severe EM-like cutaneous drug reaction triggered by lenalidomide. Lenalidomide is known to induce cutaneous side effects in $29-43 \%$ and severe cutaneous side effects in $6 \%$ [9-11]. In fact, 13 cases of SJS and toxic epidermal necrolysis (TEN) among approximately 57, 000 patients who received lenalidomide from market launch December 2005, through June 2008, were reported to Celgene company [12]. Another four cases of SJS or TEN are found in the literature [13-16]. However, EM-like reactions are very rare with only two reports with a total of four cases in the literature [12,14]. However, one of these patients had preceding herpes. Concomitant medication in this group included allopurinol which could raise doubt whether lenalidomide was the trigger [12].

The attribution of a cutaneous reaction to a particular drug often is challenging, especially in patients receiving several drugs simultaneously, and/or who have an infection. The relationship between lenalidomide and the erythema multiforme-like skin eruptions cannot 


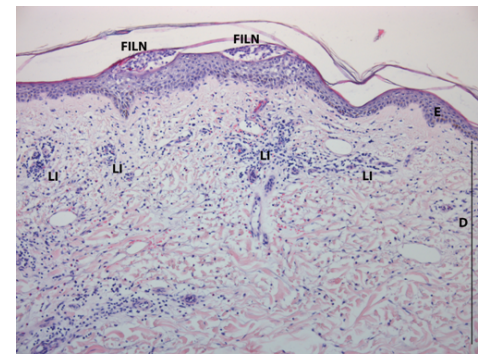

Figure 3: Biopsy specimen of a new lesion of the right knee (hematoxylin-eosin stain). Focal vesiculationwith intraepidermal lymphocytes and neutrophils. Dermal infiltrate of lymphocytes and eosinophils, accentuated around the postcapillaryvenules, extravasated erythrocytes, and discrete endothelial swelling. (E) Epidermis; (D) Dermis;(FILN) Focal vesiculation with intraepidermal lymphocytes; (LI) Leucocyte infiltration.

be ascertained. However, in this patient it is the most likely cause since the other drugs, and most notably trimethoprim/sulfamethoxazole have been given for more than 6 months and an infectious trigger could not be found. In general it is estimated that a high percentage of suspected drug eruptions can be tracked to another trigger after complete allergy testing [17]. However, for EM-like drug reactions skin tests are not indicated.

Frequent skin side effects include morbilliform exanthemas (69\%), urticarial eruptions (19\%), dermatitis (6\%) and acneiform eruptions (3\%) as documented in a retrospective study in 98 patients [9]. There are two reports of neutrophilic dermatosis (one Sweet syndrome), a case of granulomatous dermatosis, one report of blaschkitis one purpuric reaction and one case of acneiform lesions (overview Table $1[9-15,18-23])$.

The combination of lenalidomide with dexamethasone compared to lenalidomide alone did not significantly modify the incidence of cutaneous adverse events and was reported in $29 \%$ of patients treated for MM [9]. In most patients (75\%) skin eruptions occurred within the first month of treatment. However, $28 \%$ of reactions occurred after the 1 st month of treatment initiation and $12 \%$ even after the 4 th month [9]. In our case symptoms occurred in the $2^{\text {nd }}$ month. Usually skin eruptions resolve within 2-3 weeks without any further intervention. The application of antihistamines, local steroids, or a short course of oral corticosteroids may be required in some cases. In cases of persistence lenalidomide should be interrupted until the skin eruptions resolve [24].

Interestingly, even though our patient had a severe skin reaction that required cessation of drug therapy and initiation of oral steroids, the subsequent treatment cycle could be conducted without recurrence of rash. Thus, EM can be triggered by lenalidomide but even if severe may not impede further treatment of the patient with the drug.

\section{References}

1. Hazarika M, Rock E, Williams G, Dagher R, Sridhara R, et al. (2008) Lenalidomide in combination with dexamethasone for the treatment of multiple myeloma after one prior therapy. Oncologist 13: 1120-1127.

2. Aragon-Ching JB, Li H, Gardner ER, Figg WD (2007) Thalidomide analogues as anticancer drugs. Recent Pat Anticancer Drug Discov 2: 167-174.

3. Bartlett JB, Dredge K, Dalgleish AG (2004) The evolution of thalidomide and its IMiD derivatives as anticancer agents. Nat Rev Cancer 4: 314-322.

4. Horwitz SM (2008) Novel therapies for cutaneous T-cell lymphomas. Clin Lymphoma Myeloma 8 Suppl 5: S187-S192.
5. Liu WM, Henry JY, Meyer B, Bartlett JB, Dalgleish AG, et al. (2009) Inhibition of metastatic potential in colorectal carcinoma in vivo and in vitro using immunomodulatory drugs (IMiDs). Br J Cancer 101: 803-812.

6. Bartlett JB, Michael A, Clarke IA, Dredge K, Nicholson S, et al. (2004) Phase I study to determine the safety, tolerability and immunostimulatory activity of thalidomide analogue CC-5013 in patients with metastatic malignant melanoma and other advanced cancers. Br J Cancer 90: 955-961.

7. Richardson PG, Schlossman RL, Weller E, Hideshima T, Mitsiades C, et al (2002) Immunomodulatory drug CC-5013 overcomes drug resistance and is well tolerated in patients with relapsed multiple myeloma. Blood 100: 30633067.

8. Celgene Corporation, Fachinformation. Revlimid(Lenalidomid). Summit, NJ.

9. Sviggum HP, Davis MD, Rajkumar SV, Dispenzieri A (2006) Dermatologic adverse effects of lenalidomide therapy for amyloidosis and multiple myeloma. Arch Dermatol 142: 1298-1302

10. Rajkumar SV, Hayman SR, Lacy MQ, Dispenzieri A, Geyer SM, et al. (2005) Combination therapy with lenalidomide plus dexamethasone (Rev/Dex) for newly diagnosed myeloma. Blood 106: 4050-4053.

11. List A, Dewald G, Bennett J, Giagounidis A, Raza A, et al. (2006) Lenalidomide in the myelodysplastic syndrome with chromosome $5 q$ deletion. N Engl J Med 355: $1456-1465$

12. Castaneda CP, Brandenburg NA, Bwire R, Burton GH, Zeldis JB (2009) Erythema multiforme/Stevens-Johnson syndrome/toxic epidermal necrolysis in lenalidomide-treated patients. J Clin Oncol 27: 156-157.

13. Allegra A, Alonci A, Penna G, Russo S, Gerace D, et al. (2012) StevensJohnson syndrome after lenalidomide therapy for multiple myeloma: a case report and a review of treatment options. Hematol Oncol 30: 41-45.

14. Penna G, Allegra A, Romeo G, Alonci A, Cannavò A, et al. (2012) Severe dermatologic adverse reactions after exposure to lenalidomide in multiple myeloma patients with a positive HLA-DRB1*1501 and HLA-DQB1 ${ }^{*} 0602$. Acta Oncol 51: 944-947.

15. Wäsch R, Jakob T, Technau K, Finke J, Engelhardt M (2012) Stevens-Johnson/ toxic epidermal necrolysis overlap syndrome following lenalidomide treatment for multiple myeloma relapse after allogeneic transplantation. Ann Hematol 91 287-289.

16. Siniscalchi A, Tendas A, Morino L, Dentamaro T, De Bellis A, et al. (2012) Lenalidomide cutaneous adverse event: a case of Stevens-Johnson syndrome (SJS) in a primary plasma cell leukaemia patient treated with lenalidomide and dexamethasone. Support Care Cancer 20: 1585-1587.

17. Heinzerling LM, Tomsitz D, Anliker MD (2012) Is drug allergy less prevalent than previously assumed? A 5-year analysis. Br J Dermatol 166: 107-114.

18. Hoverson AR, Davis MD, Weenig RH, Wolanskyj AP (2006) Neutrophilic dermatosis (Sweet syndrome) of the hands associated with lenalidomide. Arch Dermatol 142: 1070-1071.

19. Deng A, Harvey V, Sina B, Strobel D, Badros A, et al. (2006) Interstitia granulomatous dermatitis associated with the use of tumor necrosis factor alpha inhibitors. Arch Dermatol 142: 198-202.

20. Thieu KP, Rosenbach M, Xu X, Kist JM (2009) Neutrophilic dermatosis complicating lenalidomide therapy. J Am Acad Dermatol 61: 709-710.

21. Michot C, Guillot B, Dereure O (2010) Lenalidomide-induced acute acneiform folliculitis of the head and neck: not only the anti-EGF receptor agents. Dermatology 220: 49-50.

22. Kuohung V, Goldberg LJ, Demierre MF (2011) Lenalidomide-induced purpuric eruption: a new adverse cutaneous reaction. J Am Acad Dermatol 65: 654-656.

23. Grape J, Frosch $P$ (2011) [Papular drug eruption along the lines of Blaschko caused by lenalidomide]. Hautarzt 62: 618-620.

24. Giagounidis A, Fenaux P, Mufti GJ, Muus P, Platzbecker U, et al. (2008) Practical recommendations on the use of lenalidomide in the management of myelodysplastic syndromes. Ann Hematol 87: 345-352. 